\title{
Dynamic/Jitter Assessment of Multiple Potential HabEx Structural Designs
}

J. Brent Knight/NASA MSFC

August 2017 


\section{Introduction}

- The 2020 Decadal Survey in Astronomy and Astrophysics will assess candidate large missions to follow James Webb Space Telescope (JWST) and Wide Field Infrared Space Telescope (WFIRST)

- One candidate mission is the Habitable ExoPlanet Imaging Mission (HabEx)

- This presentation describes two HabEx structural designs and results from structural dynamic analyses performed to predict Primary Mirror (PM) Secondary Mirror (SM) Line of Site (LOS) stability (jitter) due to Reaction Wheel Assembly (RWA) vibrations

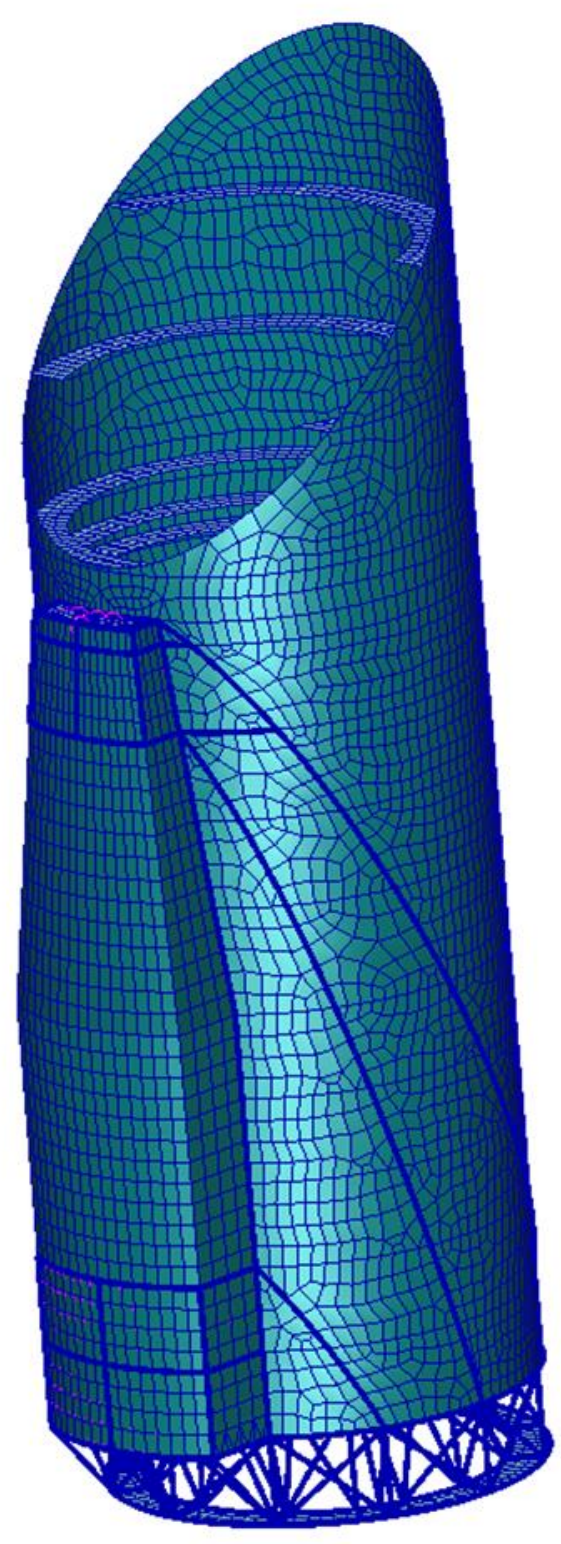




\section{Objective}

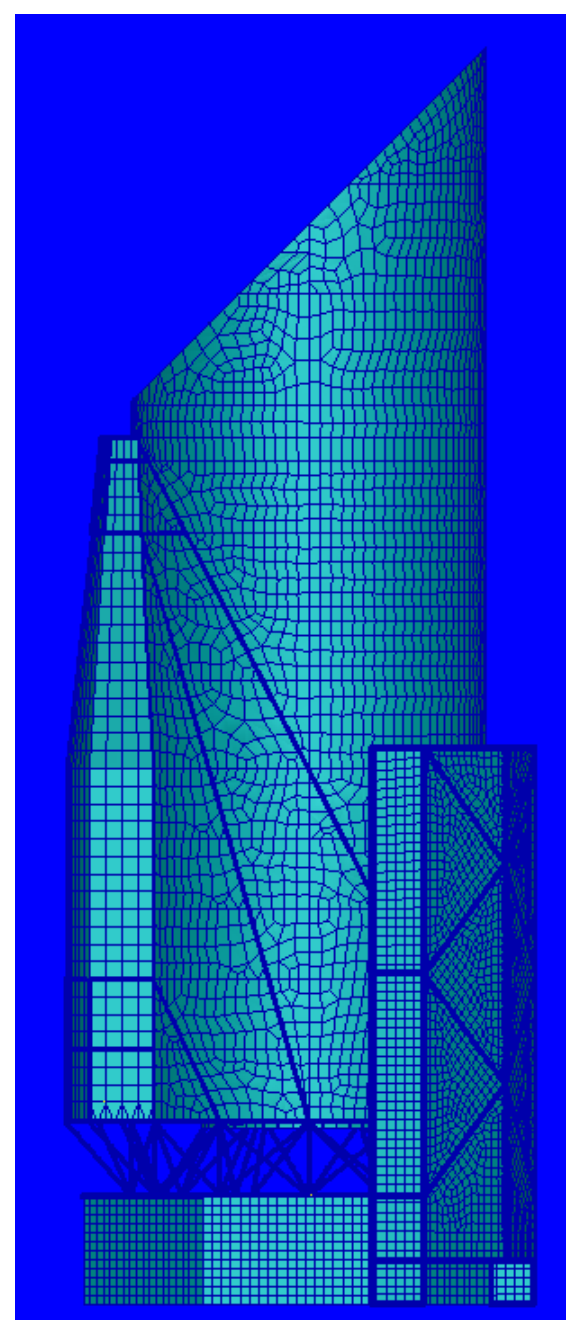

- The objective of this effort was to determine feasibility of meeting HabEx Mechanical stability requirements associated with PM/SM LOS

- PM/SM LOS alignment is required to be $\leq 5$ mas

- The $9 \mathrm{~m}$ spacing between the PM and SM add to the structural design challenge

- Requirements converted into orthogonal relative displacement vector components are:

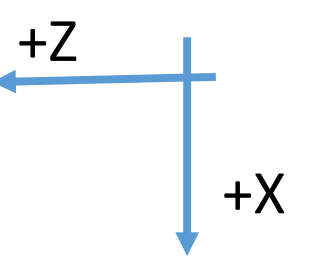

\begin{tabular}{|c|c|}
\hline Direction & Allocation \\
\hline $\mathrm{X}(\mathrm{m})$ & $2.00 \mathrm{E}-09$ \\
\hline $\mathrm{Y}(\mathrm{m})$ & $2.00 \mathrm{E}-09$ \\
\hline RSSed - De-Center $(\mathrm{m})$ & $2.80 \mathrm{E}-09$ \\
\hline $\mathrm{Z}$ - De-Space $(\mathrm{m})$ & $5.00 \mathrm{E}-09$ \\
\hline Rx $(\mathrm{rad})$ & $1.10 \mathrm{E}-09$ \\
\hline Ry $(\mathrm{rad})$ & $1.10 \mathrm{E}-09$ \\
\hline RSSed - Tip/Tilt (rad) & $1.60 \mathrm{E}-09$ \\
\hline Rz (rad) & $1.50 \mathrm{E}-09$ \\
\hline
\end{tabular}




\section{HabEx - Optical Description}

- HabEx Designs considered are $4 \mathrm{~m}$ PM and $.5 \mathrm{~m} \mathrm{SM}$ off axis optical systems

- The spacing between the PM and the SM being $9 \mathrm{~m}$ which, again, adds to the structural design /stability challenge

PM

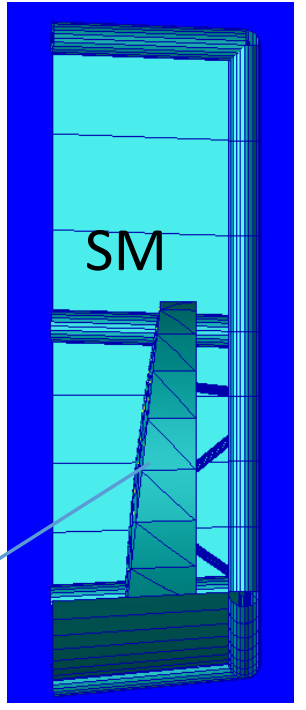

$9 \mathrm{~m}$ 


\section{Structural Designs}

- At the completion of design/analysis 1 , stability requirements were not in hand

- Therefore, how results compared to allowable alignment errors was not known

- Efforts were then initiated to further evolve the initial design

- Stiffen the path between the PM and SM without creating detrimental modes

- Two HabEx Structural Designs were analyzed

- The second design is a further evolved version of the first
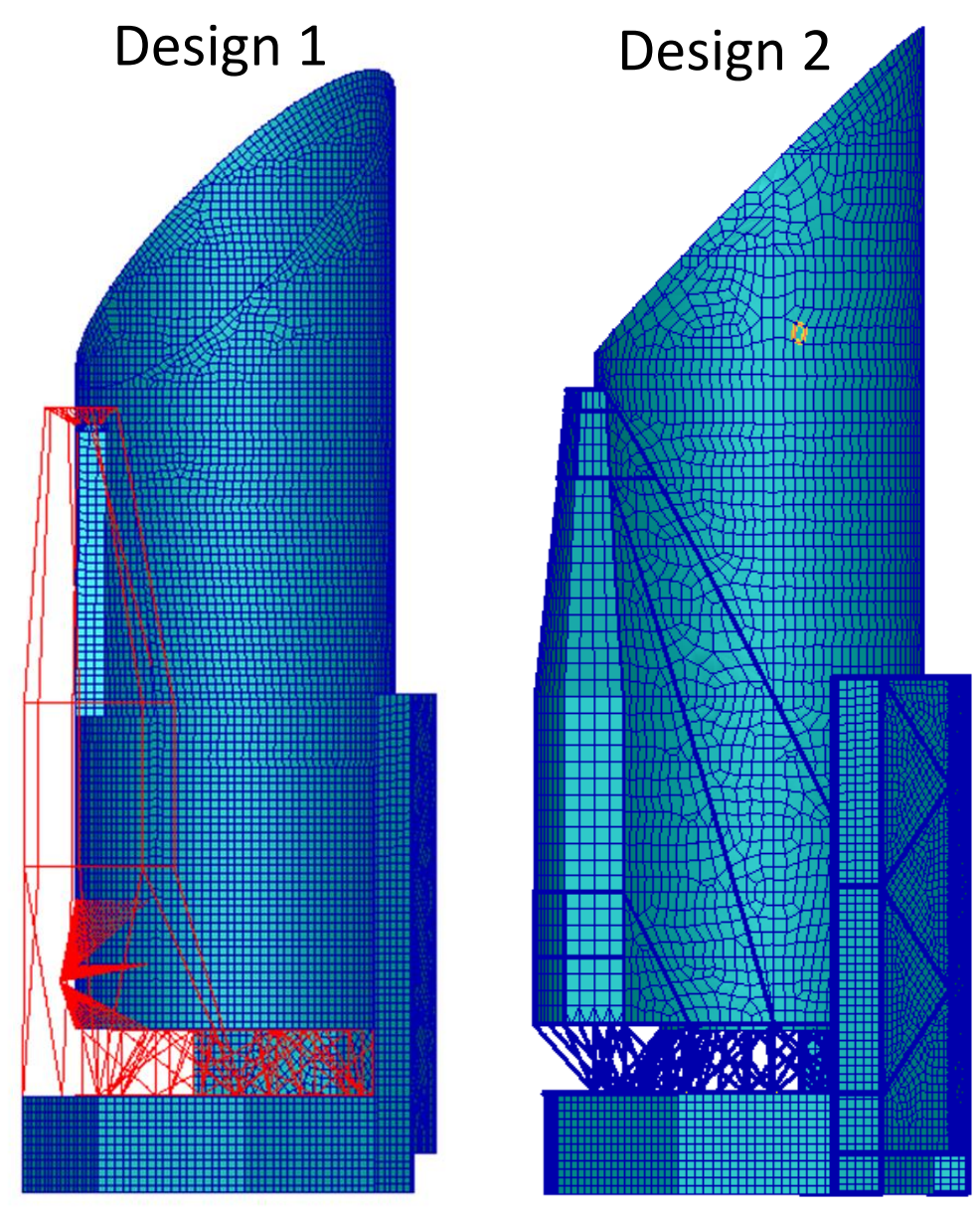

Finite Element Models (FEM) of the designs 


\section{Common Structures}

- A simplified Spacecraft design was implemented in both Design 1 and 2

- Included mass properties representing propulsion and avionics

- Included 4 load application points

- A simplified solar panel design was included in the design/model

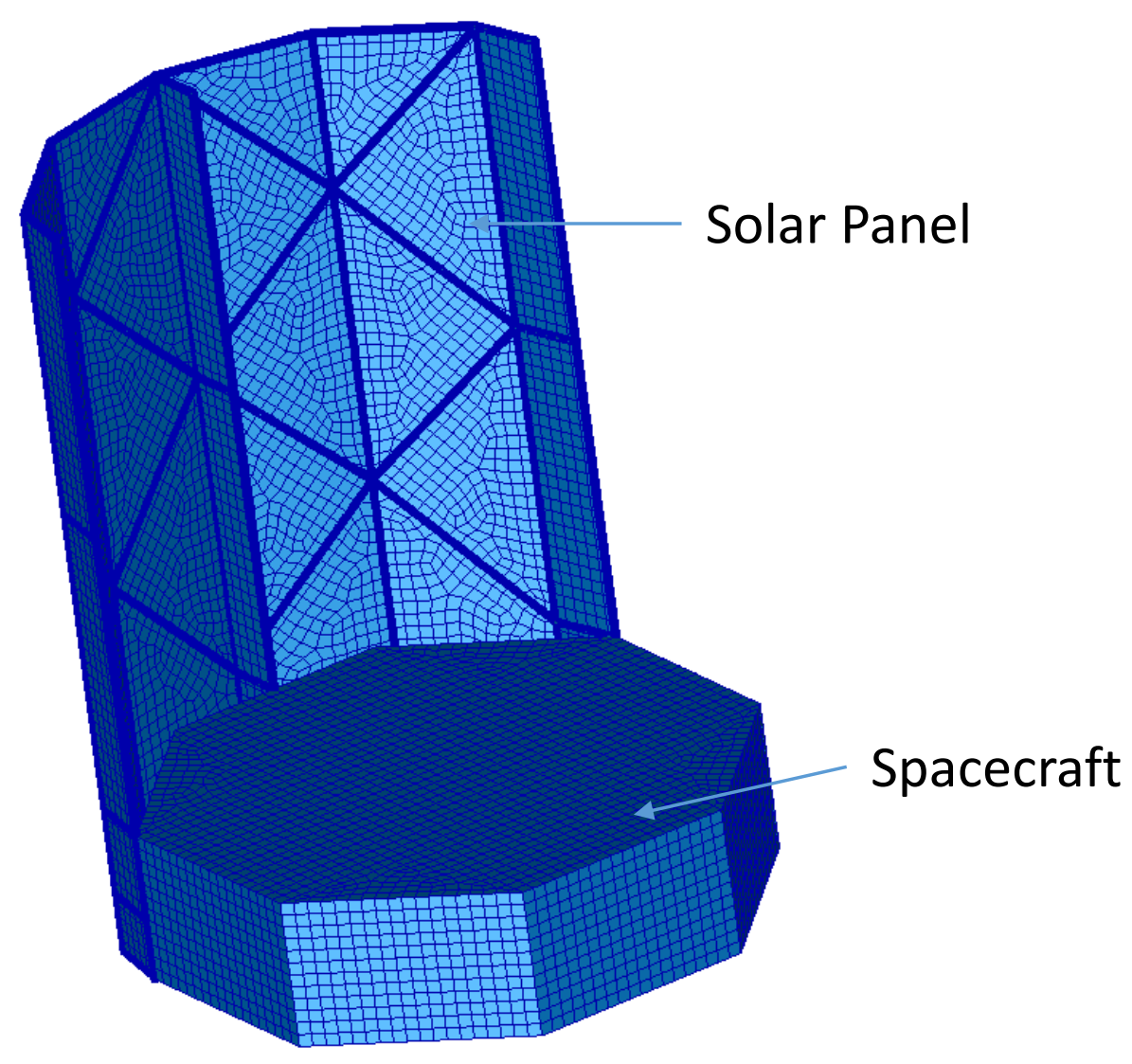




\section{Design 1}

- The tower is not connected to the Tube

- It is integral to the SC only

- The tower includes nonstructural mass (not visible) for the stray light baffle

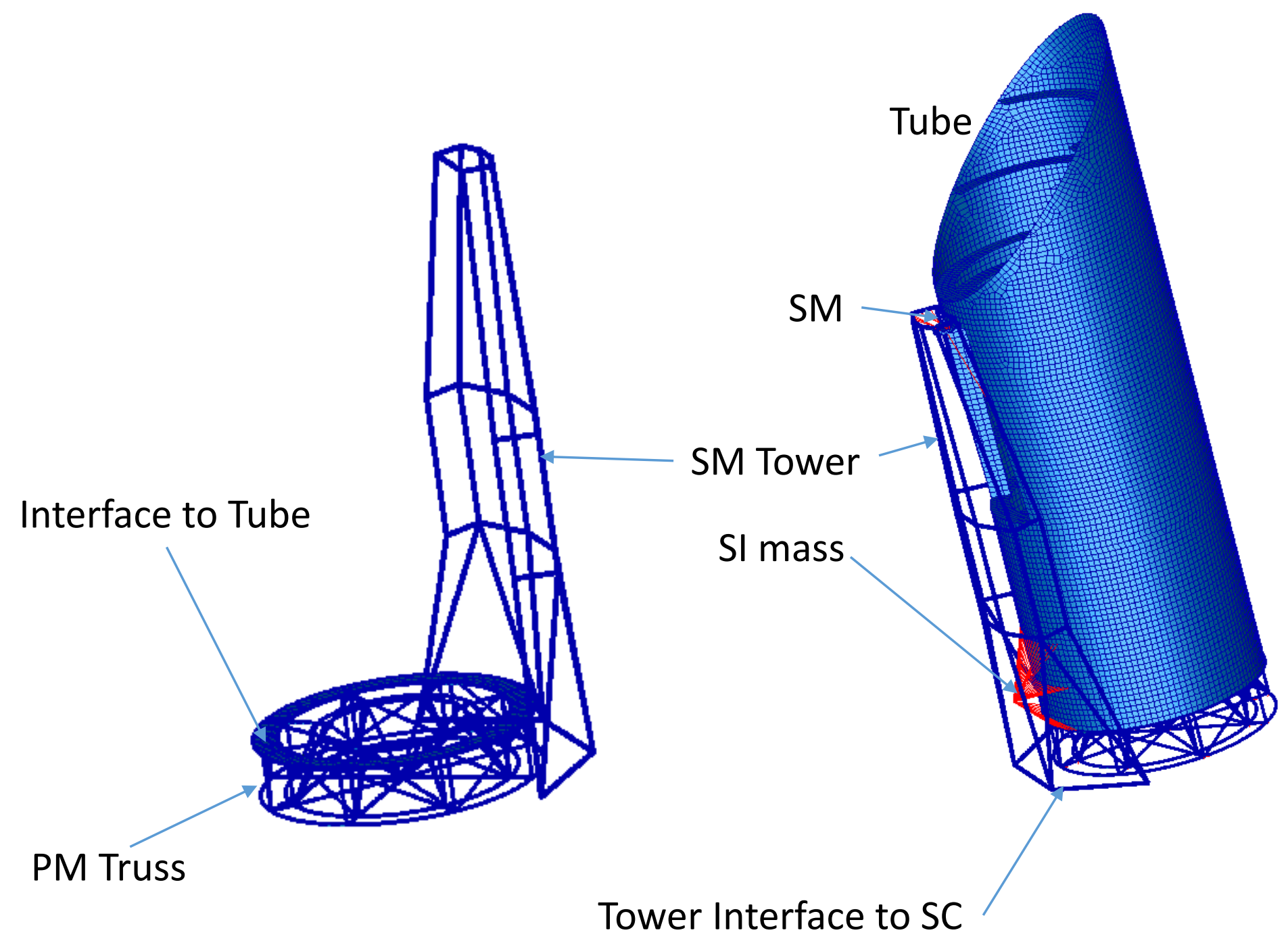




\section{Design 1}

- PM Truss

NASTRAN rigid element connecting the PM mass to the Truss

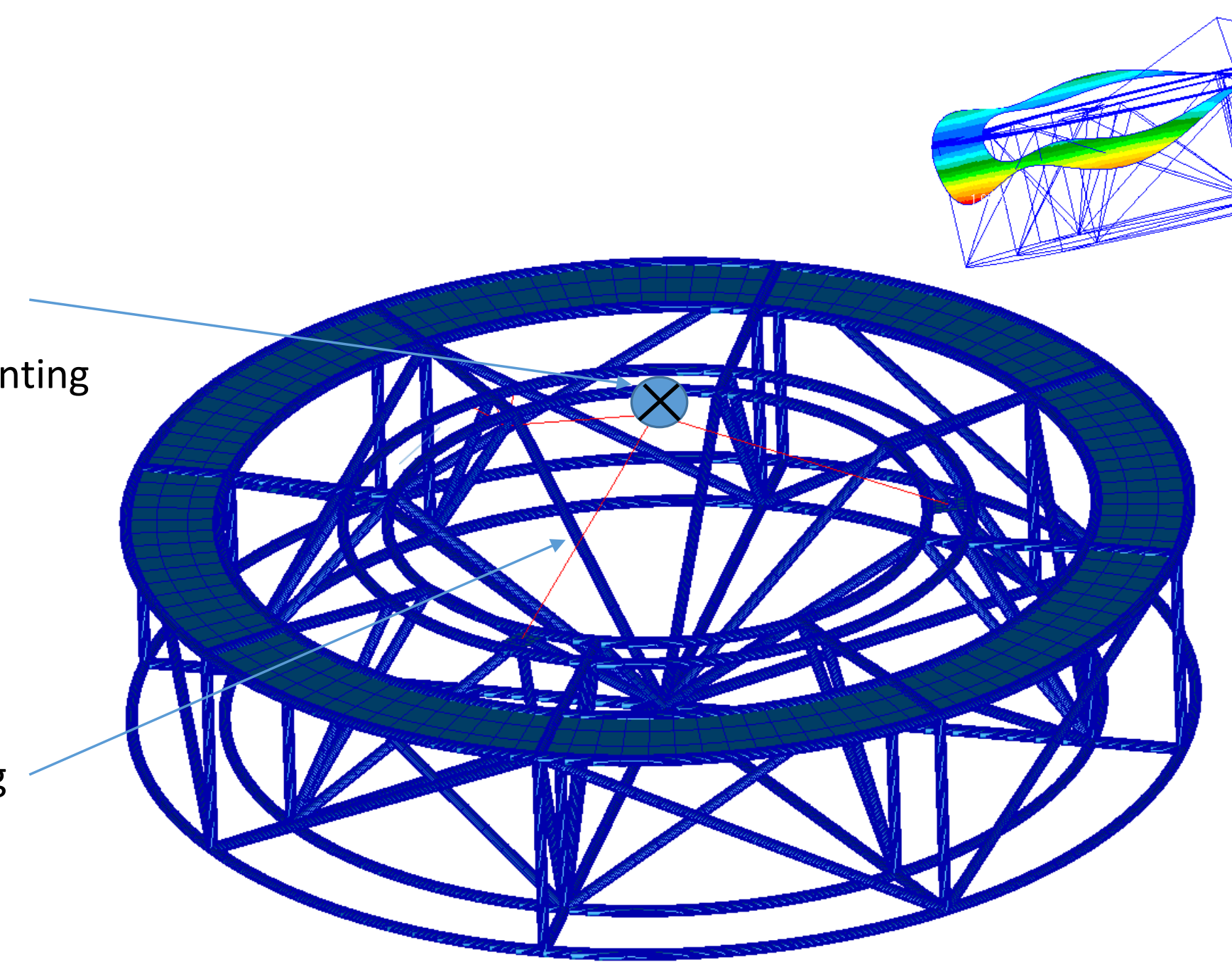

First mode at $2,000 \mathrm{Kg}$ Concentrated Mass Representing The PM 


\section{Design 1}

- SM is attached to the Tower via NASTRAN rigid elements

- Common modeling technique for a first cut

- The approach is not well suited for making extremely accurate predictions

- Tower is not connected to the tube

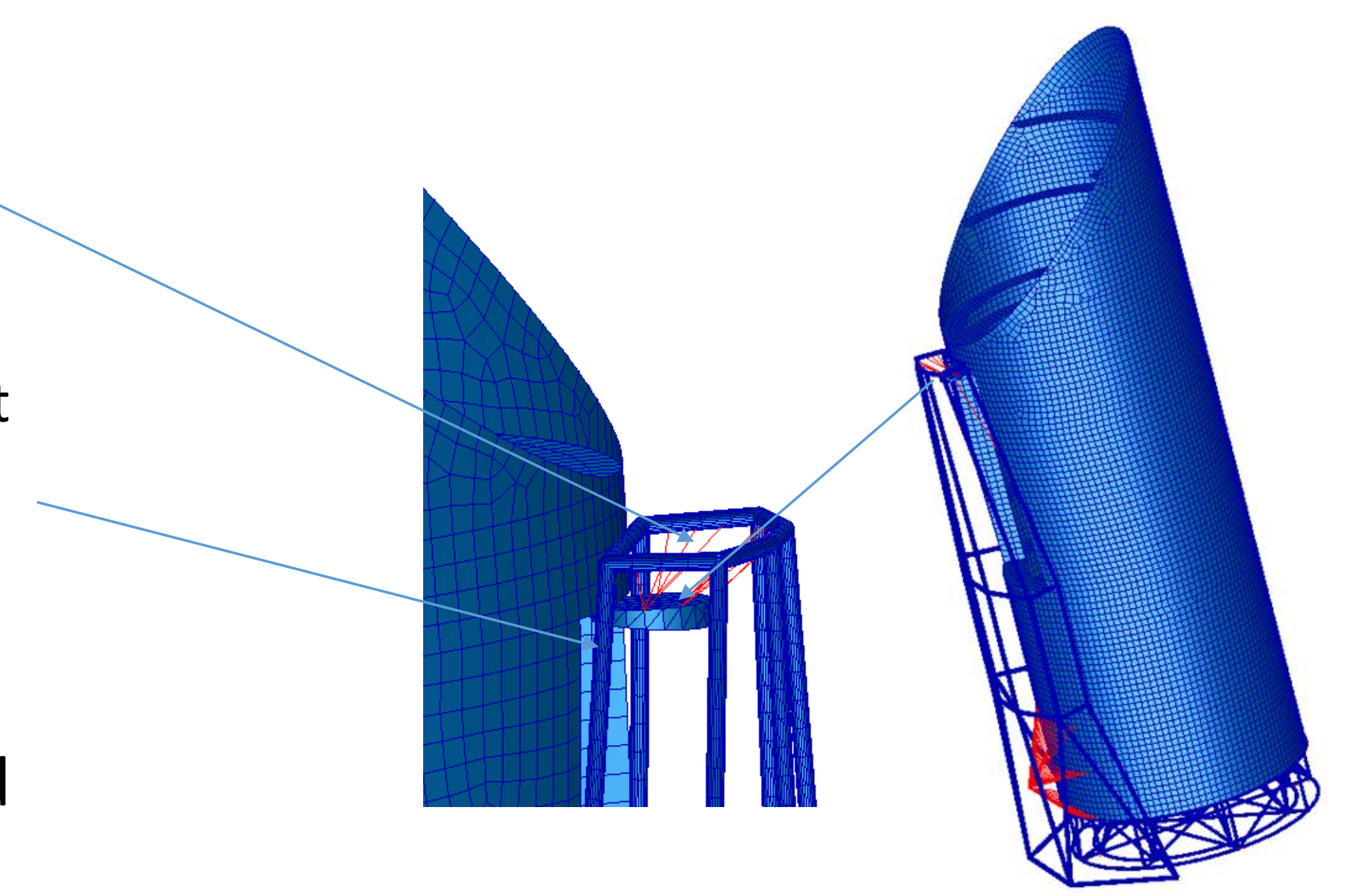




\section{Design 2 - Description}

- At this point in time, pertinent stability requirements were not in hand so effort initiated to better the design

- Design 1 modifications:

1. The SM tower was covered with structural material and integrated to the Tube

2. An exoskeleton structure that further stiffens the structural path between the PM and the SM was included

3. A detailed Finite Element Model (FEM) of the PM, created by the Arnold Mirror Modeler (AMM), was included with structural members for the PM support struts (as opposed to a rigid element)

4. A further re-designed PM truss was included to maintain $\mathrm{f} 1 \geq 40 \mathrm{~Hz}$

a. The inclusion of supports with stiffness decreased the first mode dramatically

5. Structural members (as opposed to a rigid element) were included to represent the SM support struts

a. They were scaled based on the PM supports

6. The composite material was changed to be that of JWST, M55J 954-6 at $68^{\circ} \mathrm{F}$. 


\section{Design 2 - Description}

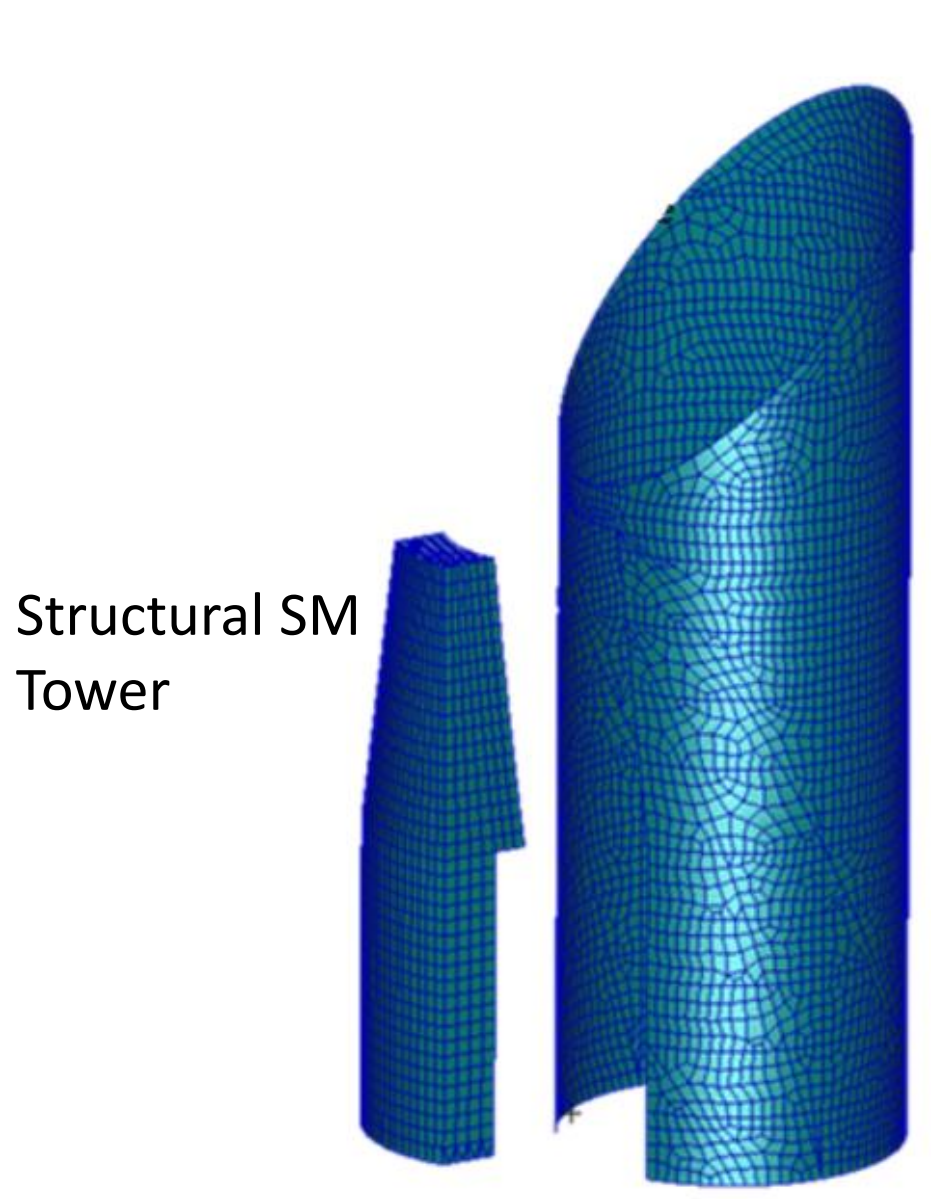

PM detailed FEM

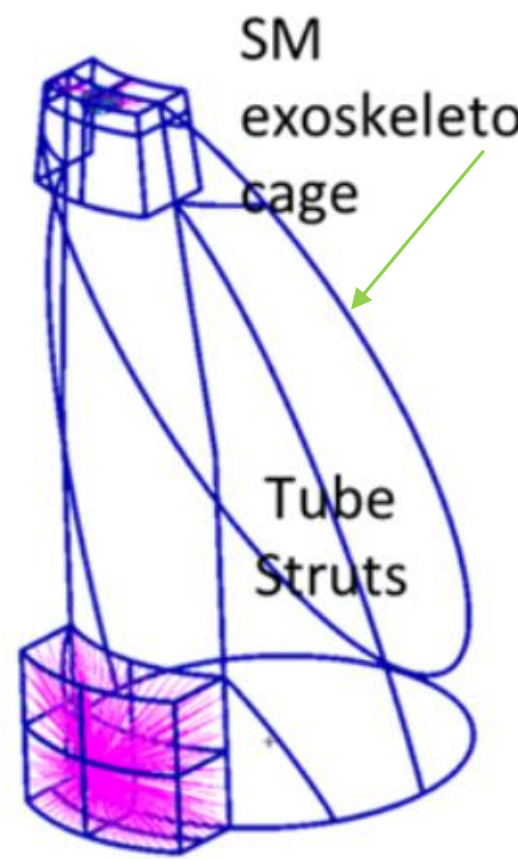

SI exoskeleton cage

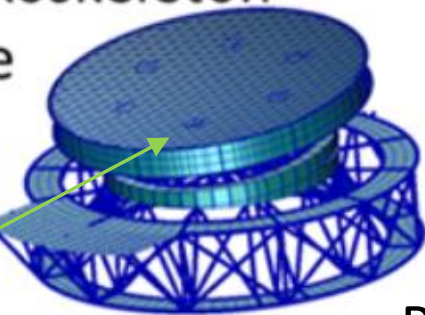

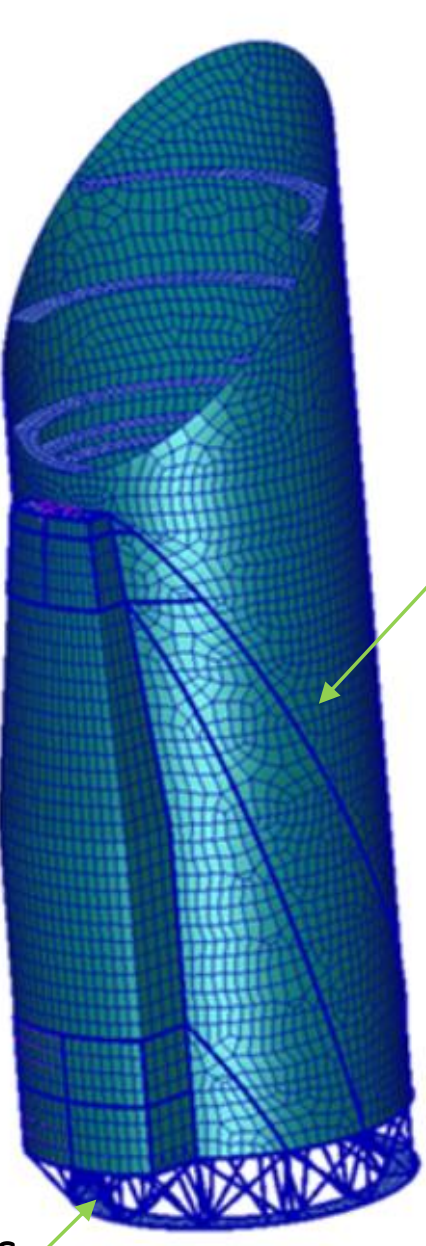

PM Truss exoskeleton

THE PM and its supports detailed design/FEM was created by the Arnold Mirror Modeler (AMM) 


\section{Design 2 - Description}

- The SM supports were,

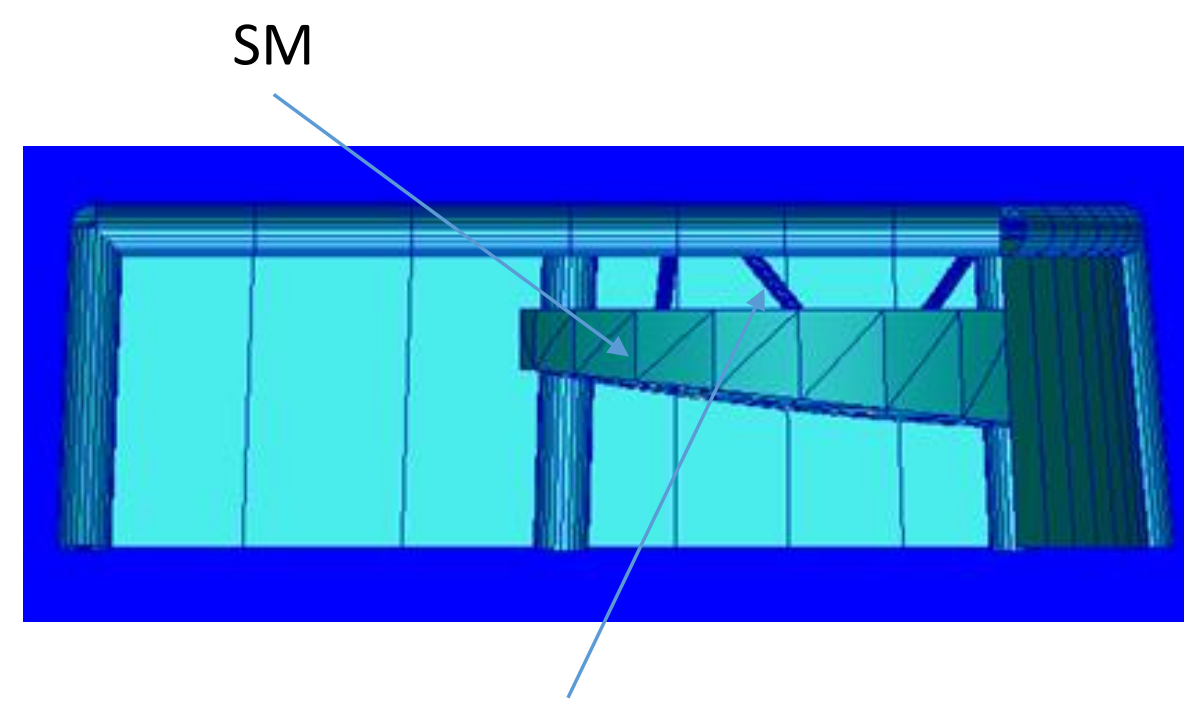
in Design 1, NASTRAN rigid elements

- They were replaced with linear finite elements

- Their dimensions were scaled from the PM supports provided by the AMM

SM attached to structural tower via structural Members (NASTRAN CBAR elements) as opposed to a rigid element 


\section{Dynamic Forcing Function}

- LOS jitter errors are due to a vibration source or sources in the system

- Performing structural dynamic analyses to predict performance associated with jitter requires a Dynamic Forcing Function (DFF)

- Guidance Navigation and Control (GN\&C) systems are expected to be the only sources of significant vibrations

- Reaction Wheels, Thrusters, Etc.

- It is assumed that HabEx will utilize a Reaction Wheel Assembly (RWA) for GN\&C

- JWST personnel communicated that their RWA proved to be challenging with respect to meeting requirements

- The allowable vibration specification for the JWST RWA was utilized in these analyses as the DFF 


\section{Dynamic Forcing Function}

- JWST RWA Vibration Limit Specification

\subsubsection{Wheel Unbalance}

After exposure to the environments defined in section 3.2 .5 of this specification, the unbalance magnitude of the RWA rotating components shall not exceed the following values:
a. Static Unbalance:
Less than $1.0(\mathrm{~g} \cdot \mathrm{cm})$
over the operating speed range.

b. Dynamic Unbalance: Less than $14.0(\mathrm{~g} . \mathrm{-cm} / 2)$ over the operating speed range.

c. The peak radial forces and moments produced by the RWA at any operating speed (including resonant conditions) shall not exceed the values listed in the table below:

Peak Radial Disturbance Limits Including Resonant Conditions

\begin{tabular}{|c|c|c|c|c|c|}
\hline $\begin{array}{c}\text { Paxameter } \\
\text { Force } \\
\left(\mathrm{F}_{\mathrm{X}}\right)\end{array}$ & $\begin{array}{c}\text { Erequency } \\
0-70 \mathrm{~Hz} \\
70-210 \mathrm{~Hz} \\
210-270 \mathrm{~Hz} \\
270-500 \mathrm{~Hz}\end{array}$ & $\begin{array}{c}\mathrm{ax} \text {. Wnit } \\
3.5 \mathrm{~N} \\
0.7 \mathrm{~N} \\
20 \mathrm{~N} \\
0.7 \mathrm{~N}\end{array}$ & 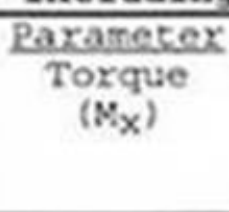 & $\begin{array}{c}\text { Erequency } \\
0-70 \mathrm{~Hz} \\
70-195 \mathrm{~Hz} \\
195-22.5 \mathrm{~Hz} \\
225-500 \mathrm{~Hz}\end{array}$ & $\begin{array}{l}\mathrm{Max} . \mathrm{hmint} \\
0.5 \mathrm{~N}-\mathrm{m} \\
0.3 \mathrm{~N}-\mathrm{m} \\
1.5 \mathrm{~N}-\mathrm{m} \\
0.3 \mathrm{~N}-\mathrm{m}\end{array}$ \\
\hline
\end{tabular}

\subsubsection{Axial Induced Vibration}

The peak force (amplitude) produced by the RWA in the direction parallel to the its spin axis shall not exceed $0.2 \mathrm{~N}$ within the frequency range $2.200 \mathrm{~Hz}$, when measured at constant speeds that are within the operational speed range and that are free of major structural resonances. The peak axial force produced by the RWA at any operating speed (including resonant conditions) shall not exceed the following limit values:

\begin{tabular}{|l|c|c|c|c|c|c|}
\hline Prequency Range (1n Hz): & $0-150$ & $150-195$ & $195-225$ & $225-300$ & $300-500$ \\
\hline Axial Force (Fz) Linit: & $0.7 \mathrm{~N}$ & $4.5 \mathrm{~N}$ & $45 \mathrm{~N}$ & $4.5 \mathrm{~N}$ & $0.7 \mathrm{~N}$ \\
\hline
\end{tabular}

Scott Knight of Ball Aerospace 


\section{Dynamic Forcing Function}

- Use of the JWST RWA is considered conservative

- Between the time the JWST RWA vibration specification was written and the time a potential HabEx mission selects a RWA (assuming it uses RW's) available RWA's should be more precise (lower emitted vibrations) than that of JW

- Presumably that technology, like others, will evolve over decades

- Hence, use of existing JWST RWA data is conservative

- If HabEx engineers opt to utilize thrusters or some other means to achieve GN\&C it is likely that doing so will be done to better performance

- Hence, use of existing JWST RWA data is conservative 


\section{Analysis}

- Frequency Response Analysis (FRA) were performed to predict relative motion between the center of the PM and the center of the SM

- At each frequency analyzed the FEM is loaded with a sinusoidal force of unit maximum amplitude

- The mean Displacement of the surface of the PM and the SM are calculated due to the input sinusoidal force

- The relative motion between the two is determined from those results

- Those data were scaled by the DFF

- A FRA is effectively a "transfer function" (TF) approach 


\section{Analysis}

- Frequency response analyses were performed on both designs

- The system FEM was in the free-free configuration as it would be in service

- The FEM is not fixed or grounded

- $1 \%$ Damping was used

- Results were output at $1 \mathrm{~Hz}$ intervals

- 4 DFF Applications Points
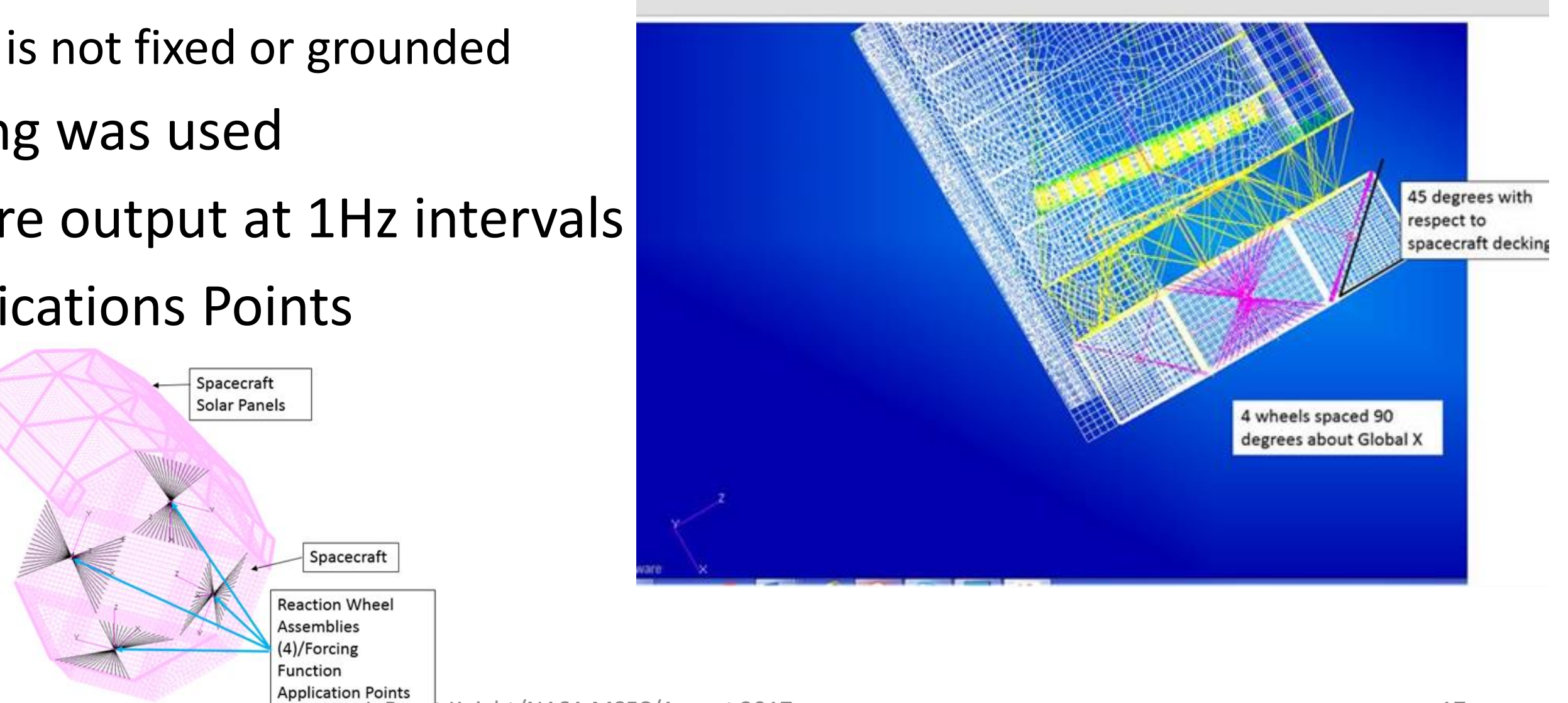


\section{Analysis}

- Uncertainty Factor

- Due to the very small order of magnitude ( $\left.\mathrm{nm}^{\prime} \mathrm{s}\right)$ of data being predicted and the use of standard material properties, a 15\% uncertainty factor was applied to results

- Isolation

- JWST has reported that with a number of passive isolation systems a net $80 \mathrm{~dB}$ reduction in vibratory responses has been achieved

- Therefore $80 \mathrm{~dB}$ reduction has been assumed in these analyses

- Should be a reasonable philosophy

- Assuming pertinent technologies and capabilities evolve between now and when they are needed perhaps better than 80 can be achieved

$$
-80 d b=20 \log \left(\frac{\text { isolated response }}{\text { predicted response }}\right)
$$

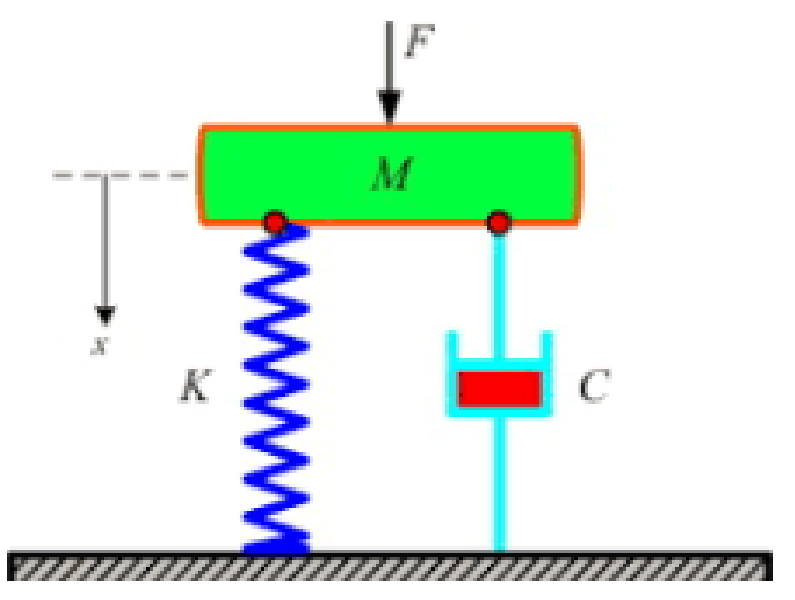




\section{Analysis}

\section{- Conservative application of the DFF data}

- JWST data included axial and radial forces as well as torque spectra

- JWST allowable axial and torque vibration levels were applied in all cases simultaneously with some combination of a radial force vectors at each of the 4 reaction wheels

- The orientation of the vibratory load radial to each of four the wheels was varied to determine the worst combination of 4 orientations.

- Initially the load vector was changed in 1 degree increments

- After the worst combination was determined, the increment was changed to 10 degrees and that converged to the same answer

- From that time forward a 10 degree increment was utilized

- This approach is perceived as conservative
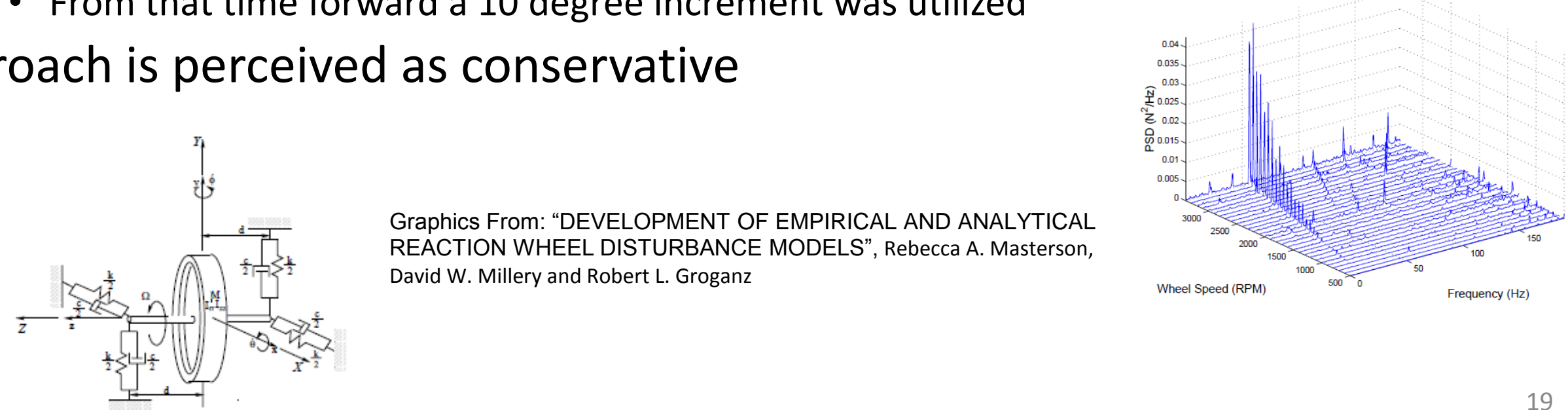


\section{Results}

- Sample of relative displacements from 1 to $500 \mathrm{~Hz}$

- At each frequency, from 1 to $500 \mathrm{~Hz}$, in increments of $1 \mathrm{~Hz}$ and at each modal frequency, the $X, Y$, and $Z$ displacements were output for the PM and the SM

- The same was done for rotational motion

- The sum of those numbers at each frequency is the relative displacement
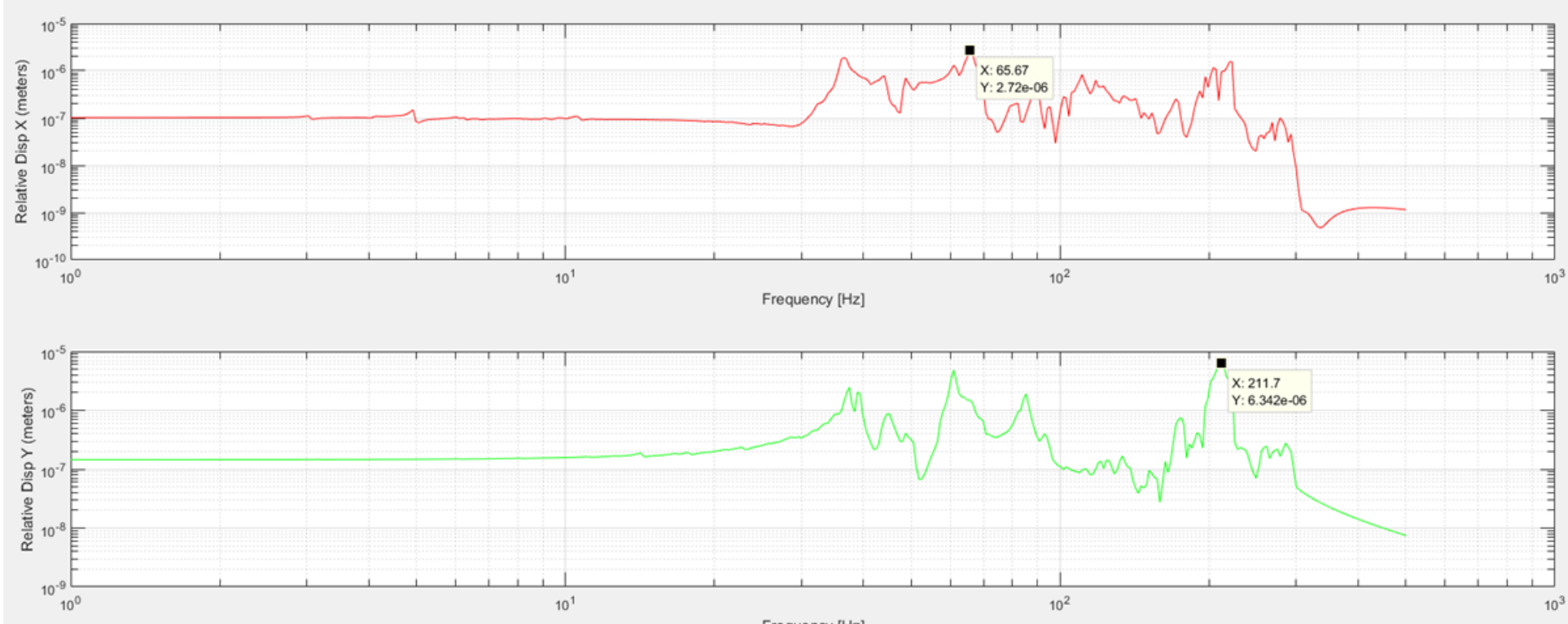

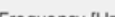

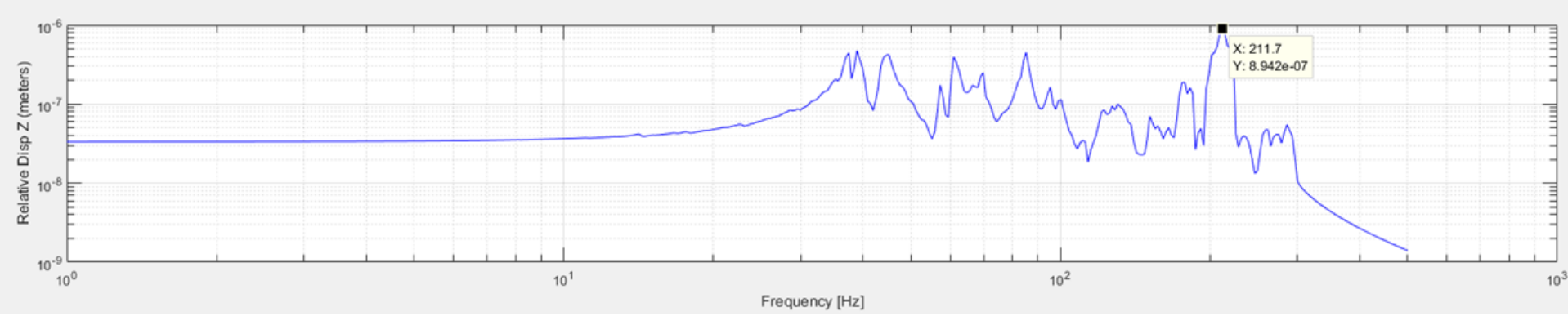




\section{Results}

- Design 1 summary

- Tower independent of tube

- SM Tower has less structural material than design 2

\begin{tabular}{|c|c|c|c|}
\hline \multicolumn{3}{|c|}{ Design 1 } \\
\hline \multicolumn{2}{|c|}{ Linear $(\mathrm{m})$} & \multicolumn{3}{c|}{ Rotation (rad) } \\
\hline $\mathrm{X}$ & $2.78 \mathrm{E}-10$ & $\mathrm{Rx}$ & $6.26 \mathrm{E}-12$ \\
\hline $\mathrm{Y}$ & $1.40 \mathrm{E}-09$ & $\mathrm{Ry}$ & $1.25 \mathrm{E}-11$ \\
\hline RSSed X\&Y - De-Center & $1.43 \mathrm{E}-09$ & RSSed Rx\&Ry-Tip/Tilt & $1.40 \mathrm{E}-11$ \\
\hline Z - De-Space & $4.38 \mathrm{E}-10$ & $\mathrm{Rz}$ & $6.39 \mathrm{E}-12$ \\
\hline
\end{tabular}

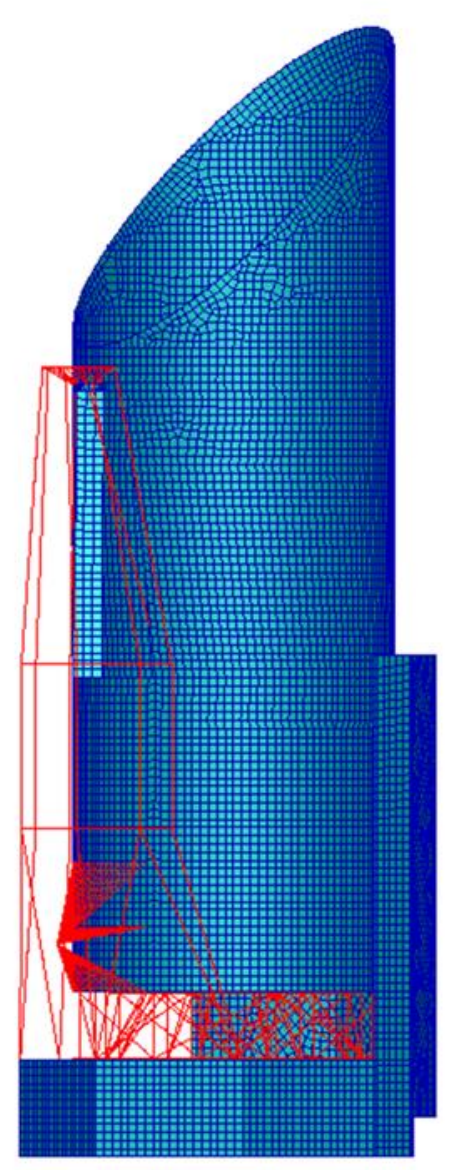




\section{Results}

- Design 2 summary

- Stiffer SM tower

- Tower/Tube stiffness integrated

- Notably more stiffness between the PM and SM

- Exoskeleton

\begin{tabular}{|c|c|c|c|}
\hline \multicolumn{4}{|c|}{ Design 2} \\
\hline \multicolumn{2}{|c|}{ Linear (m) } & \multicolumn{2}{|c|}{ Rotation (rad) } \\
\hline $\mathrm{x}$ & $3.13 \mathrm{E}-10$ & $\mathrm{Rx}$ & $6.26 \mathrm{E}-12$ \\
\hline $\mathrm{Y}$ & $7.29 \mathrm{E}-10$ & Ry & 4.96E-12 \\
\hline RSS X\&Y - De-Center & $7.93 \mathrm{E}-10$ & RSSed Rx\&Ry - Tip/Tilt & $7.98 \mathrm{E}-12$ \\
\hline Z & $1.03 \mathrm{E}-10$ & $\mathrm{Rz}$ & 3. $25 \mathrm{E}-12$ \\
\hline
\end{tabular}

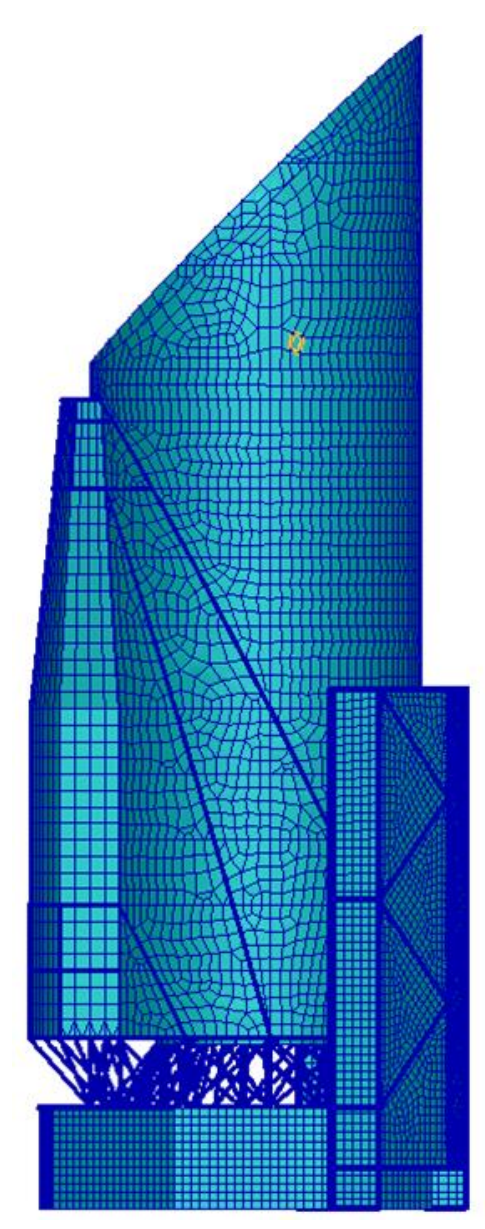




\section{Results}

- Comparison of Design 1 and Design 2

- With the exception of $Y$ decenter Design 2 out performs Design 1

- Design 2 RSS ${ }^{\text {ed }}$ decenter results out performs Design 1

- Design 2 is more stable than Design 1

\begin{tabular}{|c|c|c|c|}
\hline Direction & Design 1 & Design 2 & Design 2 vs. Design 1 \\
\hline $\mathrm{X}(\mathrm{m})$ & $1.40 \mathrm{E}-09$ & $3.13 \mathrm{E}-10$ & $22.30 \%$ \\
\hline $\mathrm{Y}(\mathrm{m})$ & $2.78 \mathrm{E}-10$ & $7.29 \mathrm{E}-10$ & $261.98 \%$ \\
\hline RSSed - De-Center $(\mathrm{m})$ & $1.43 \mathrm{E}-09$ & $7.93 \mathrm{E}-10$ & $55.47 \%$ \\
\hline Z - De-Space $(\mathrm{m})$ & $4.38 \mathrm{E}-10$ & $1.03 \mathrm{E}-10$ & $23.46 \%$ \\
\hline Rx $(\mathrm{rad})$ & $1.25 \mathrm{E}-11$ & $6.26 \mathrm{E}-12$ & $49.91 \%$ \\
\hline Ry $(\mathrm{rad})$ & $6.26 \mathrm{E}-12$ & $4.96 \mathrm{E}-12$ & $79.23 \%$ \\
\hline RSSed - Tip/Tilt (rad) & $1.40 \mathrm{E}-11$ & $7.98 \mathrm{E}-12$ & $56.97 \%$ \\
\hline Rz (rad) & $6.39 \mathrm{E}-12$ & $3.25 \mathrm{E}-12$ & $50.90 \%$ \\
\hline
\end{tabular}




\section{Results}

- Comparison of Design 2 and pertinent requirements

\begin{tabular}{|c|c|c|c|}
\hline Direction & Design 2 & Allocation & \% of Allocation \\
\hline $\mathrm{X}(\mathrm{m})$ & $3.13 \mathrm{E}-10$ & $2.00 \mathrm{E}-09$ & $15.64 \%$ \\
\hline $\mathrm{Y}(\mathrm{m})$ & $7.29 \mathrm{E}-10$ & $2.00 \mathrm{E}-09$ & $36.46 \%$ \\
\hline RSSed - De-Center $(\mathrm{m})$ & $7.93 \mathrm{E}-10$ & $2.80 \mathrm{E}-09$ & $28.33 \%$ \\
\hline $\mathrm{Z}$ - De-Space $(\mathrm{m})$ & $1.03 \mathrm{E}-10$ & $5.00 \mathrm{E}-09$ & $2.06 \%$ \\
\hline Rx $(\mathrm{rad})$ & $6.26 \mathrm{E}-12$ & $1.10 \mathrm{E}-09$ & $0.57 \%$ \\
\hline Ry $(\mathrm{rad})$ & $4.96 \mathrm{E}-12$ & $1.10 \mathrm{E}-09$ & $0.45 \%$ \\
\hline RSSed - Tip/Tilt $(\mathrm{rad})$ & $7.98 \mathrm{E}-12$ & $1.60 \mathrm{E}-09$ & $0.50 \%$ \\
\hline $\mathrm{Rz}(\mathrm{rad})$ & $3.25 \mathrm{E}-12$ & $1.50 \mathrm{E}-09$ & $0.22 \%$ \\
\hline
\end{tabular}

- Both designs satisfied the LOS stability requirements

- Design 2 notably out performed Design1 


\section{Discussion of Results}

- Conservatisms

- Material property UF was utilized

- Input loads (DFF) applied in many combinations and results enveloped

- JW RWA data is conservative WRT this activity

- RSSed maximum vector components that did not necessarily occur at the same frequency

- $1 \%$ damping is thought to be conservative (in general 1-3\% are commonly used)

- All DFF applied at the same frequency simultaneously

- Un-conservatisms

- $80 \mathrm{~dB}$ reduction based on a simplistic application of that analytically may be over optimistic

- With the conservatisms utilized plenty of margin still exists

- In the worst case, predictions were only about $1 / 3$ the required maximum limit 


\section{Conclusions}

- The analyses performed to assess feasibility of the global HabEx structure demonstrated that both designs satisfy PM/SM LOS stability requirements

- Design 2, intuitively, is strategically stiffer than Design 1

- That which keeps the PM and SM in alignment was stiffened and integrated

- SM Tower stiffened integrated with the Tube

- The base of the PM support structure was directly tied to that of the SM via the exoskeleton

- As anticipated, Design 2 outperformed Design 1

- Knowing that in a real system, when hardware is built, and this order of magnitude of performance is required, numerous unforeseen and unpredictable impacts to performance should be anticipated

- With this in mind, even though Design 1 satisfies requirements and Design 2 would likely be more expensive, Design 2 is the current baseline 


\section{Acknowledgements}

- NASA/MSFC/ES22 personnel supporting this effort are extremely busy with SLS activities and likely always multitasking to the extreme

- Nonetheless, when asked if they could support this activity they found a way to integrate their efforts/contributions to HabEx in between their never ending SLS list of tasks

- The efforts of Andy Singleton, Melissa Therrell, Ron Hunt, and Kate Caldwell were considered above and beyond and are greatly appreciated

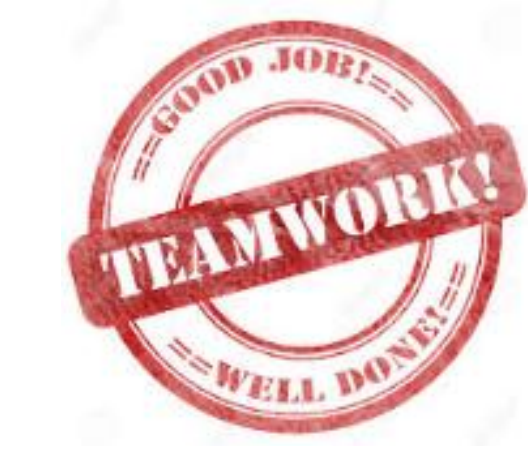

